\title{
Standardized Three-Dimensional Lateral Distraction Test: Its Reliability to Assess Medial Canthal Tendon Laxity
}

\author{
Xiaoyi Hou ${ }^{1,2}$ - Alexander C. Rokohl ${ }^{2} \cdot$ Marius M. Meinke ${ }^{2} \cdot$ Jinhua Liu $^{3}$ • \\ Senmao $\mathrm{Li}^{2} \cdot$ Wanlin $\mathrm{Fan}^{2} \cdot$ Ming $\mathrm{Lin}^{4} \cdot$ Renbing $\mathrm{Jia}^{4} \cdot$ Yongwei Guo ${ }^{5}$ (D) \\ Ludwig M. Heindl ${ }^{2,6}$
}

Received: 14 April 2021 / Accepted: 19 June 2021 / Published online: 7 July 2021

(C) The Author(s) 2021

\begin{abstract}
Background Assessment of MCT laxity is critical to the surgery options. Our study aimed to analyze the reliability of measuring medial canthal tendon (MCT) laxity by using a novel standardized three-dimensional lateral distraction test (3D-LDT).

Methods Forty-eight Caucasian volunteers (25 males and 23 females, 96 eyes) between 22 and 84 years of age $(55.6 \pm 18.6$ years old) were included in our study. From a neutral position, the lower eyelid was gently pulled
\end{abstract}

Xiaoyi Hou and Alexander C. Rokohl have contributed equally and both should be considered as first authors.

Yongwei Guo and Ludwig M. Heindl have contributed equally and both should be considered as corresponding authors.

Yongwei Guo

yongwei-guo@zju.edu.cn

$\triangle$ Ludwig M. Heindl

ludwig.heindl@uk-koeln.de

1 Department of Ophthalmology, West China Hospital, Sichuan University, Chengdu, China

2 Department of Ophthalmology, Faculty of Medicine and University Hospital Cologne, University of Cologne, Kerpener Strasse 62, 50937 Cologne, Germany

3 Department of Ophthalmology, Xi' an Fourth Hospital, Xi'an, Shaanxi, China

4 Department of Ophthalmology, Ninth People's Hospital, Shanghai Jiao Tong University School of Medicine, Shanghai, China

5 Eye Center, Second Affiliated Hospital, School of Medicine, Zhejiang University, 88 Jiefang Road, Hangzhou 310009 , China

6 Center for Integrated Oncology (CIO) Aachen-BonnCologne-Duesseldorf, Cologne, Germany laterally along a horizontal line to define the most distracted position of the lower punctum. Both in the neutral and distracted position, standardized 3D images were acquired for each subject by two observers, and each image were measured twice by two raters. Four landmarks and six corresponding linear measurements were evaluated for intra-rater, inter-rater, and inter-method reliability.

Results Intra-rater, inter-rater and inter-method reliability analyses of 3D-LDT revealed an intraclass correlation of more than $95 \%$, a mean absolute difference of less than 1 $\mathrm{mm}$, and a technical error of measurement of less than $1 \mathrm{~mm}$. Measurements of relative error (2.59-12.04\%) and relative technical error $(1.83-16.05 \%)$ for the inter-landmarks distance from pupil center to the lower punctum were higher than those from limbus nasal center to the lower punctum (6.13-30.39 and 4.34-26.85\%, respectively).

Conclusions This study provided high reliability of the three-dimensional lateral distraction test (3D-LDT) for assessing medial canthal tendon (MCT) laxity, which were never evaluated by digital imaging system.

Level of Evidence IV This journal requires that authors assign a level of evidence to each article. For a full description of these Evidence-Based Medicine ratings, please refer to the Table of Contents or the online Instructions to Authors www.springer.com/00266.

Keywords Medial canthal tendon laxity · Lateral distraction test . Three dimensional stereophotogrammetry $\cdot$ Reliability $\cdot$ Eyelid 


\section{Introduction}

The medial canthal tendon (MCT) is a stripe of fibrous tissue that insert into the orbicularis oculi muscle as a ligament [1]. Aging may cause laxity of MCT, which eventually contribute to the etiology of lower eyelid ectropion, specifically medial ectropion and the accompanying epiphora $[2,3]$. Proper assessment of MCT laxity is critical to the surgery options. A deficient diagnosis of neglecting the laxity [4] and thereby incomplete correction ectropion may lead to recurrent of epiphora and redness of the inferonasal conjunctiva as a result [5].

Lateral distraction test (LDT) was the gold traditional method for assessing the laxity of MCT, which was performed by pulling the lower eyelid laterally along a horizontal direction and observing how far the lower punctum can be pulled in relation to the cornea nasal limbus $[6,7]$ Results may vary depending on the subject of the issue, and quantitative analysis is difficult. Several studies [4, 6-12] have investigated the grading method of MCT laxity. However, no universally grading scale or format is accepted at present for recording the laxity, and the result is usually just noted as being present or not.

Noninvasive three-dimensional (3D) digital photogrammetry has recently gained much interest in anthropometry and is beginning to replace the classical anthropometric techniques, including the caliper and twodimensional (2D) imaging measurements [13]. Several 3D digital imaging systems have been developed and already used successfully in craniofacial centers all over the world [14-20]. In addition to linear distances and angles calculation, 3D imaging system dramatically offers calculation of surface curves, surface areas, volumes and volume change from the human surface. Recently, the reliability and accuracy of applying VECTRA ${ }^{\mathrm{M} 3}$ (Canfield Scientific, Inc., Parsippany, NJ), a type of 3D stereo-photography system, in maxillofacial anthropometry has been validated in several studies [14, 21-26]. More specifically, the feasibility and reliability of employing this 3D imaging system in the periocular region of this 3D imaging system has also been verified by previous studies [13, 27, 28].

As far as we know, the MCT laxity has never been quantified by using 3D imaging system, and there is an increasing need for developing an appropriate way to quantify it. Hence, based on the successful application of this 3D imaging technique, we developed a novel 3D lateral distraction test (3D-LDT) to modify the assessment of MCT laxity. In addition, we want to investigate the reliability and reproductivity of this 3D-LDT, so as to utilize this new technique in the clinical routine for assessing the laxity of MCT. Therefore, the purposes of this study were to investigate the reliability of 3D camera when operating the LDT, and to assess the interobserver reproducibility of LDT using 3D stereophotogrammetry.

\section{Material and Methods}

\section{Subjects}

Forty-eight Caucasian volunteers (25 males and 23 females, 96 eyes) between 22 and 84 years of age $(55.6 \pm 18.6$ years old) were included in our study. Each participant had normal eyelids, no history of previous eyelid or ocular surgery, no history of ocular disease or long term of eye drops application. Individuals with facial pathologies, malformations, severe asymmetry, or medical histories of injuries modifying the periocular morphology were excluded. Subjects were randomly recruited from the Department of Ophthalmology, University Hospital of Cologne, Germany. The study protocol adhered to the Declaration of Helsinki and was approved by the Institutional Review Board of the University of Cologne.

\section{Data Collection}

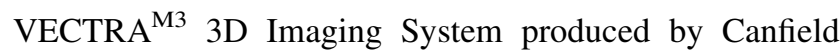
Scientific, Inc., Parsippany, NJ, was applied for capturing the data of the observed periocular surface [27]. Calibration [13] of the VECTRA system was performed daily, prior to patient arrival, or whenever the system has been moved or altered. Following calibration, each participant was positioned according to the manufacturer's instructions. A skilled operator performed all the captures according to the manufacturer's instructions in standard environment under the same ambient lighting circumstance. All the 3D facial models were elaborated by the VECTRA Analysis Module (VAM) software for surface topography measuring, analyzing, and manipulating.

\section{Neutral Position}

For each volunteer, the former 3D images were taken without any expression and any distraction test of the lower eyelid mentioned above (Neutral position, NP). Before image acquisition, we marked the lower punctum of both eyelids with a black pen for further analyzes. During the acquisition, each participant was asked to keep the eyes simultaneously opening and to look forward into the mirror hanging in the upper middle of the 3D camera. Then, the operator pressed the bottom and got the image for the NP (Fig. 1a). 
Table 1 Definition of landmarks

\begin{tabular}{|c|c|}
\hline Landmarks & Definition \\
\hline Pc & Pupillary center \\
\hline Ln & Medial corneoscleral limbus point \\
\hline $\mathrm{Pu}$ & $\begin{array}{l}\text { The mark on the skin representing the position of lower } \\
\text { punctum }\end{array}$ \\
\hline $\mathrm{Pu}^{\prime}$ & The distracted position of the lower punctum \\
\hline nPc-Pu & $\begin{array}{l}\text { Horizontal distance from pupil center }(\mathrm{Pc}) \text { to lower } \\
\text { punctum }(\mathrm{Pu}) \text { in NP }\end{array}$ \\
\hline $\mathrm{nLn}-\mathrm{Pu}$ & $\begin{array}{l}\text { Horizontal distance from medial corneoscleral limbus } \\
\text { point }(\mathrm{Ln}) \text { to lower punctum }(\mathrm{Pu}) \text { in NP }\end{array}$ \\
\hline $\mathrm{dPc}-\mathrm{Pu}^{\prime}$ & $\begin{array}{l}\text { Horizontal distance from pupil center }(\mathrm{Pc}) \text { to lower } \\
\text { punctum }\left(\mathrm{Pu}^{\prime}\right) \text { in LDT }\end{array}$ \\
\hline $\mathrm{dLn}-\mathrm{Pu}{ }^{\prime}$ & $\begin{array}{l}\text { Horizontal distance from limbus nasal center }(\mathrm{Ln}) \text { to } \\
\text { lower punctum }\left(\mathrm{Pu}^{\prime}\right) \text { in LDT }\end{array}$ \\
\hline $\mathrm{n} * \mathrm{Pc}-\mathrm{Pu}$ & $\begin{array}{l}\text { Horizontal distance from pupil center }(\mathrm{Pc}) \text { to lower } \\
\text { punctum }\left(\mathrm{Pu}^{\prime}\right) \text { of the opposite eye in LDT }\end{array}$ \\
\hline $\mathrm{n} * \mathrm{Ln}-\mathrm{Pu}$ & $\begin{array}{l}\text { Horizontal distance from medial corneoscleral limbus } \\
\text { point }(\mathrm{Ln}) \text { to lower punctum }\left(\mathrm{Pu}^{\prime}\right) \text { of the opposite eye } \\
\text { in LDT }\end{array}$ \\
\hline
\end{tabular}

$n$ normal distance; $n^{*}$ normal distance in LDT; $d$ distraction distance; $N P$ neutral position; $L D T$ lateral distraction test.

\section{Distracted Position: Lateral Distraction Test (LDT)}

Lateral distraction test (LDT) was the golden method for assessing the MCT [8]. The examiner gently pulled the lateral part of the lower eyelid along a horizontal direction until it can no longer be pulled to the lateral any further. Each participant was placed the same way as NP in front of the VECTRA ${ }^{\mathrm{M} 3}$ camera, while the 3D images were taken when operating the LDT (Fig. 1b).

\section{Landmarks and Linear Distances}

Three basic landmarks were used in each image, including pupillary center $(\mathrm{Pc})$, punctum $(\mathrm{Pu})$ and the medial corneoscleral limbus point (Ln). In the neutral position (NP), the fourth landmark was the intersection of the horizontal line through the pupil center and the vertical line through the neutral punctum $(\mathrm{Pu})$. The linear distance from $\mathrm{Pu}$ to the vertical line across $\mathrm{Pc}$ was recorded $\mathrm{nPc}-\mathrm{Pu}$ and the linear distance from $\mathrm{Pu}$ to vertical line across $\mathrm{Pc}$ recorded $\mathrm{nLn}-\mathrm{Pu}$ in NP, which were the basis for the following measurements (Fig. 2a). In the lateral distraction test (LDT), the fourth landmark was the intersection of the horizontal line through the pupil center and the vertical line through the distracted punctum $\left(\mathrm{Pu}^{\prime}\right)$. The linear distance from $\mathrm{Pu}^{\prime}$ to the vertical line across $\mathrm{Pc}$ was recorded $\mathrm{dPc}-$
Fig. 1 Three-dimensional Neutral Position (NP) and Lateral Distraction Test (LDT) for a 32-year-old male participant. a NP images were taken without any expression and any distraction test of the lower eyelid. Three landmarks $(\mathrm{Pc}, \mathrm{Ln}, \mathrm{Pu})$ were included. Linear distances were based on these landmarks. Dotted lines are vertical lines across medial corneoscleral limbus and dashed lines are vertical lines across pupil center. b LDT images were taken when performing the distraction test of the lower eyelid mentioned above. Three landmarks $\left(\mathrm{Pc}, \mathrm{Ln}, \mathrm{Pu}^{\prime}\right)$ on the tested eye and 3 landmarks ( $\mathrm{Pc}$, $\mathrm{Ln}, \mathrm{Pu}$ ) on the opposite eye were included in our research. $\mathrm{Pu}$ (purple arrow) represented for the marked resting punctum and $\mathrm{Pu}^{\prime}$ represented for the distracted punctum (blue arrow)

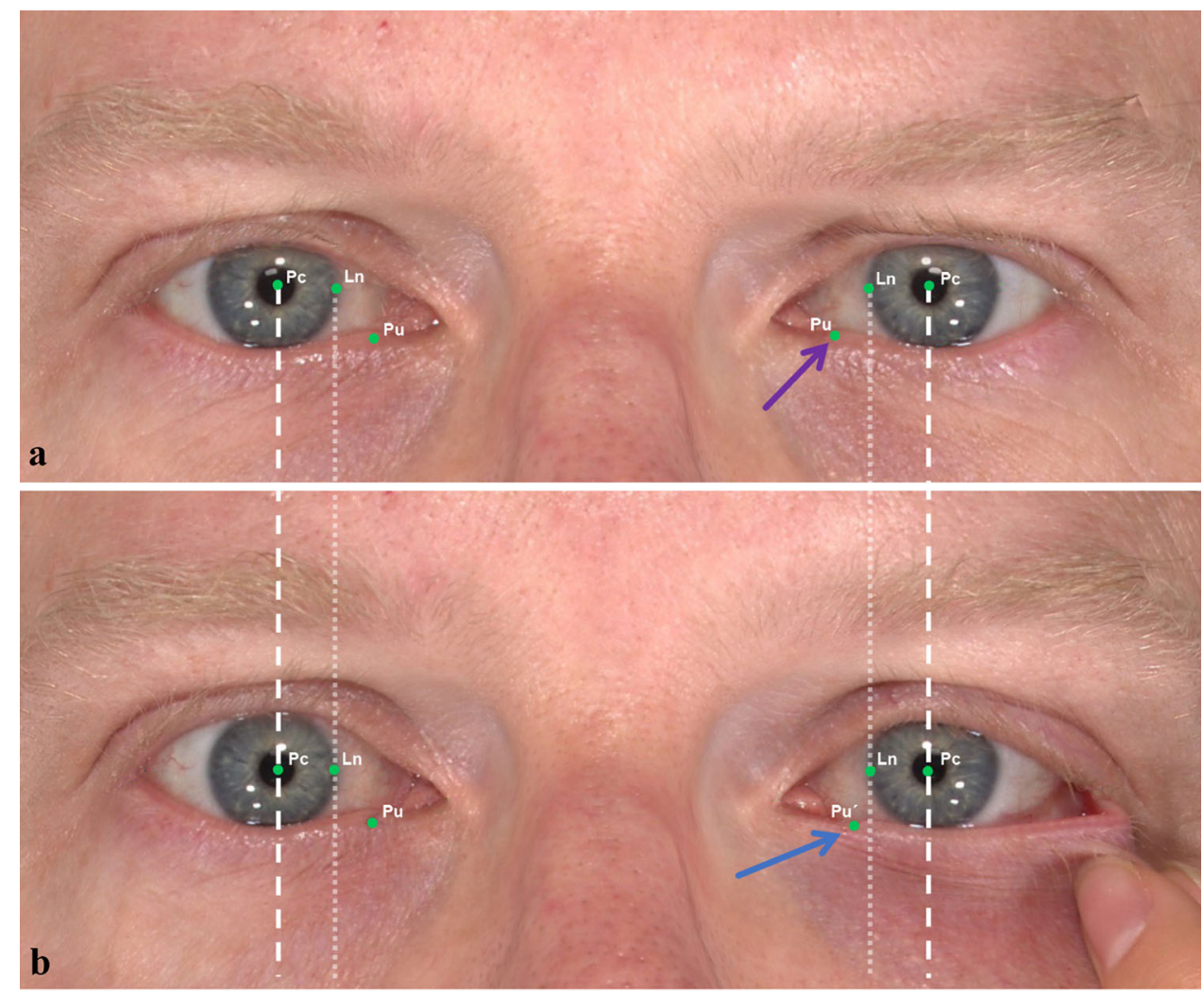


Fig. 2 Three-dimensional Neutral Position (NP) and Lateral Distraction Test (LDT) for an 80-year-old male participant. a NP images were taken without any facial expression. b LDT images were taken when performing the distraction test of the lower eyelid. The position is recorded with 'negative (-) ', if the pu' is lateralized to the vertical line through the medial corneoscleral limbus. The position is recorded with 'positive (+) ', if the $\mathrm{pu}^{\prime}$ is medialized to the vertical line through the medial corneoscleral limbus. The figure shows a positive $(+)$ location of the (pu') for this participant (blue arrow)

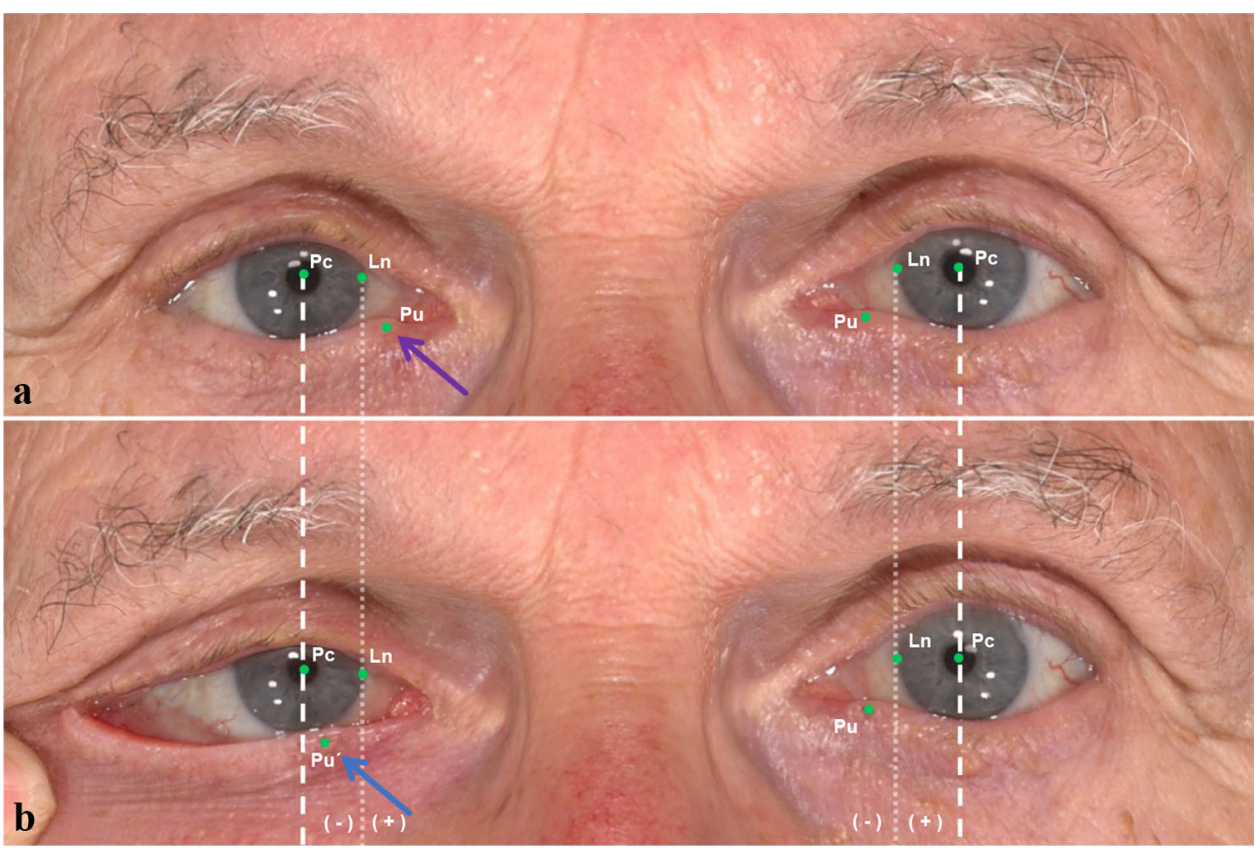

Table 2 Summary of reliability estimates evaluated

\begin{tabular}{lr}
\hline Statistic & Equation \\
\hline Intraclass correlation coefficient (ICC) & $B / B+W$ \\
Mean absolute difference (MAD) & $\left|X_{1}-X_{2}\right|$ \\
Technical error of measurement (TEM) & $\sqrt{\left(\sum D^{2}\right) / 2 N}$ \\
Relative error measurement (REM) & $M A D / X_{3} \times 100$ \\
Relative TEM (\% TEM or rTEM) & $T E M / X_{3} \times 100$ \\
\hline
\end{tabular}

$B$ between-measurement variance; $W$ within measurement variance; [7] $D$ difference between measurements; $N$ number of eyes or subjects measured; $X 1$ mean for rater 1 (session 1, or session 2 of capture 1); X2 mean for rater 2 (session 2, or session 2 of capture 2); X3 grand mean.

$\mathrm{Pu}^{\prime}$ and the linear distance from $\mathrm{Pu}^{\prime}$ to vertical line across $\mathrm{Ln}$ recorded dLn-Pu' in LDT (Fig. 2b). The linear distance from $\mathrm{Pu}^{\prime}$ to the vertical line across $\mathrm{Pc}$ was recorded $\mathrm{n} * \mathrm{Pc}$ $\mathrm{Pu}$ and the linear distance from $\mathrm{Pu}$ to vertical line across $\mathrm{Ln}$ recorded $n * \mathrm{Ln}-\mathrm{Pu}^{\prime}$ in LDT for the opposite eyes (Table 1).

\section{Intra- and Inter-Rater Reliability of Lateral Distraction Test by Using VECTRA ${ }^{\mathrm{M} 3}$ System}

To avoid the bias of the distraction test caused by imprecision [14] and inaccuracy [13], we analyzed the intra- and inter-rater precision and accuracy of lateral distraction test by using VECTRA ${ }^{\mathrm{M} 3}$ 3D system. For intra-rater reliability, initial inter-landmark measurements were acquired on 3D images and calculated by the first rater (X. Hou) using the VAM software. These measurements were repeatedly calculated at least two weeks later by the same observer on the same images. For inter-rater reliability, both initial interlandmark measurements on the same images were acquired by the first rater (X. Hou) and the second rater (A.C. Rokohl).

\section{Inter-Methods Reliability of Lateral Distraction Test by Using VECTRA ${ }^{\mathrm{M} 3}$ System}

Comparison between neutral and distracted position plays a vital role as possible error might occur when performing different captures in different times or by different observers. Hence, we performed two sets of comparison.

The first comparison was performed in the images of NP. Each subject got two captures by the same observer (X.H.) at an interval time of about $45 \mathrm{~min}$, and a new calibration was performed in the gap. Then, landmarks and inter-landmarks measurements for each capture were performed by the same observer (X.H.) after 24 hours.

Secondly, LDT of the same participant was performed by two examiners X.H. and the second observer (A.C. R.) at an interval of approximately $45 \mathrm{~min}$. Then, both 
observers (X.H. and A.C.R.) put the landmarks and performed the measurements on their own-operated images of the same participant using VAM software. Both observers (X.H. and A.C.R.) were masked to the others' measurements and very experienced in using VECTRA $^{\mathrm{M} 3} 3 \mathrm{D}$ system.

\section{Potential Clinical Indications}

Both 3D-NP and 3D-LDT were performed on patients with different clinical status including post-operative images for pre-operative images for patients with involutional ectropion (Fig. 3), and patients with basal cell carcinoma who underwent Huges plastic surgery (Fig. 4).

\section{Statistical Analyses}

Each participant got four pictures. The former two pictures of NP were performed by the first author (X.H.), the latter two pictures of LDT were performed by the first author and the second observer (A.C.R.), separately. We calculated five statistics (Table 2) to evaluate inter-rater, intra-rater and inter-method reliabilities [29,30]. Inter-rater and intrarater reliability were performed on the same images. Intermethod reliability included comparing two neutral captures by one observer and comparing LDT performed by X.H. and A.C.R. The intraclass correlation coefficient (ICC) demonstrates high reliable result when close to 1 and low reliable result when close to 0 [18]. Mean absolute difference (MAD) was computed by equally dividing the absolute difference between two measurements. The relative error measurement (REM) was computed by averaging the MAD using the grand mean of two measurements for a specific variable and multiplying the result by 100 [13]. The technical error of measurement (TEM) was calculated as $\left(\sqrt{\left(\sum D^{2}\right) / 2 N}\right)$, in which $\mathrm{D}$ is the difference between independent measurements and $\mathrm{N}$ is the count of measured subjects [14]. This statistic can be explicated similar to the standard deviation [15]. The relative TEM (\%TEM or rTEM) has been introduced to compare imprecision of different variables due to the positive association between the size of measurement and TEM. It was also computed by averaging the TEM for a specific variable by its grand mean and multiplying by 100 . According to the scale initiated by Andrade et al., these results were defined into five categories: less than $1 \%$, excellent; $1-3.9 \%$, very good; 4-6.9\%, good; 7-9.9\%, moderate; and more than $10 \%$ poor [31, 32].

Microsoft Excel 2016 for MAC (Microsoft Corp., Redmond, WA, USA) was applied to record all the original data of inter-landmarks measurements. Subsequently, Statistical analysis was performed by SPSS version 23
Fig. 3 Three-dimensional photographs in neutral position (a) and performing the lateral distraction test (b) were taken in a 72 -year-old female participant before correction surgery of medial ectropion (left eye), which was secondary to a Basel cell carcinoma excision 6 months ago. An obvious medial ectropion was shown in the NP and the punctum displacement was calculated as $2.12 \mathrm{~mm}$ by our landmark system
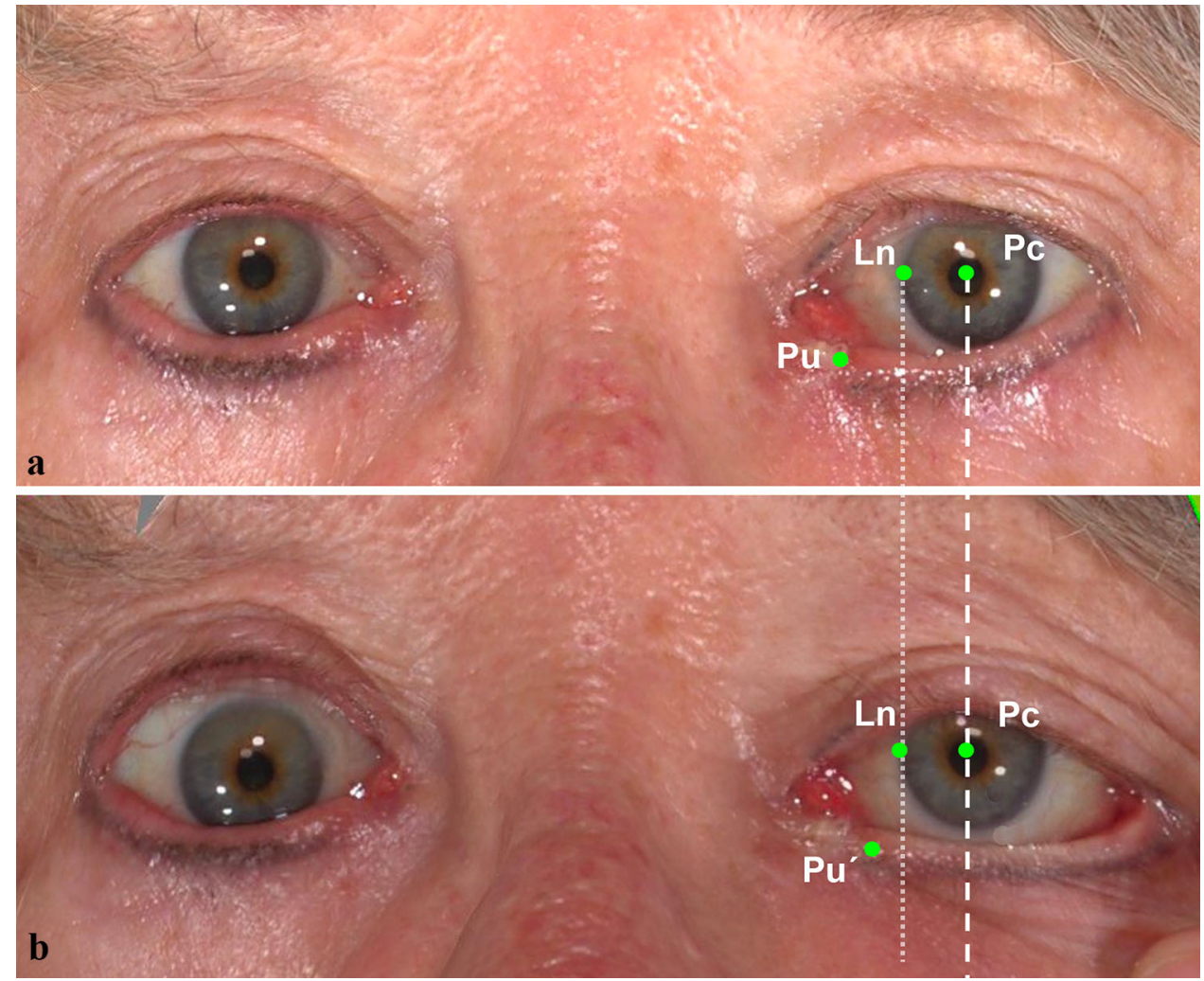
Fig. 4 Three-dimensional photographs in neutral position (a) and performing lateral distraction test (b) were taken in a 61-year-old female participant who underwent Hughes plastic surgery following basal cell carcinoma excision (right eye) three years ago. A good postoperative position was shown in the NP and the LDT

displacement was calculated as $2.96 \mathrm{~mm}$ by our landmark system
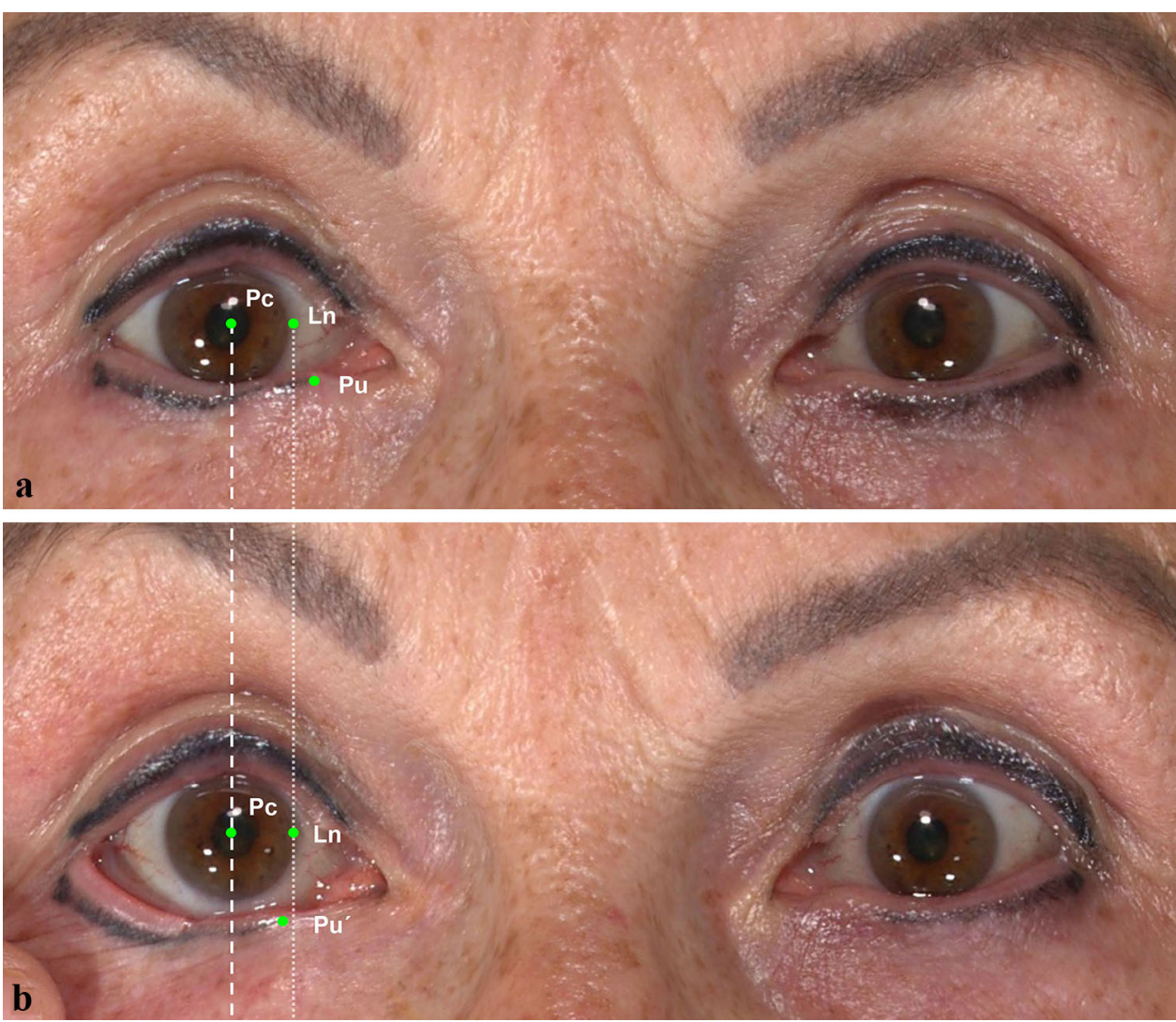

software (IBM Corp., Armonk, NY, USA). Intra-rater, inter-rater, and inter-method differences of all the measurements were calculated using this system. Paired-sample $t$ test was performed for normally distributed data and Wilcoxon signed rank tests for paired data were applied for non-normally distributed data. $P$ values $\leq 0.05$ were considered statistically significant.

\section{Results}

Demographic features of the study subjects are shown in Table 3. A total of 48 participants was included in our study. Study participants were between 22 and 84 years of age $(55.6+18.6$ years old $)$. The ratio of men to women was nearly equal, and most study participants were white, non-Hispanic. Results of reliability were divided into three categories including intra-rater, inter-rater and intermethod reliability. Table 4 demonstrated the ICC and mean differences of intra-rater, inter-rater, and intra-method for all inter-landmark measurements. Estimates of MAD, TEM, REM, and \%TEM is shown in Table 5. Although statistically significant differences were found between intra-rater, inter-rater, or inter-method measurements, the different magnitudes for all of them were less than $1 \mathrm{~mm}$ and not clinically significant.
Table 3 Demographic characteristics of study participants

\begin{tabular}{ll}
\hline Categories & Count \\
\hline Age & \\
Range (years old) & $22-84$ yrs \\
Mean \pm SD & $55.6 \pm 18.6 \mathrm{yrs}$ \\
Sex & \\
Male & $25(52.1 \%)$ \\
Female & $23(46.9 \%)$ \\
Total & 48 \\
Race/ethnicity & \\
White/non-hispanic & $48(100.0 \%)$ \\
Other & 0 \\
\hline
\end{tabular}

\section{Intra-Rater Reliability for 3D-LDT}

Intra-rater reliability (ICC) for measurements taken from 3D surface images was greater than 0.95 for five of the six measurements: equal to 0.95 for distance from nasal limbus to punctum in LDT (Table 4).

The MAD were less than $1 \mathrm{~mm}$ for all the six measurements. Two measurements (distance from pupil center to punctum both in NP and LDT) of the six measurements 
Table 4 Intraclass correlation coefficient (ICC) and mean differences (Dmean) of intra-rater, inter-rater inter-methods across all measurements on three-dimensional images

\begin{tabular}{|c|c|c|c|c|c|c|c|c|c|c|}
\hline \multicolumn{2}{|c|}{ Landmarks } & \multicolumn{3}{|l|}{ Intra-rater } & \multicolumn{3}{|l|}{ Inter-rater } & \multicolumn{3}{|l|}{ Inter-methods } \\
\hline & & ICC(CI95\%) & $\begin{array}{l}\mathrm{D}- \\
\text { mean }\end{array}$ & $\begin{array}{l}P \\
\text { value }\end{array}$ & $\mathrm{ICC}(\mathrm{CI} 95 \%)$ & D-mean & $\begin{array}{l}P \\
\text { value }\end{array}$ & $\mathrm{ICC}(\mathrm{CI} 95 \%)$ & $\begin{array}{l}\text { D- } \\
\text { mean }\end{array}$ & $\begin{array}{l}P \\
\text { value }\end{array}$ \\
\hline \multirow[t]{2}{*}{ NP } & $\mathrm{nPc}-\mathrm{Pu}$ & $0.98(0.96-0.99)$ & 0.05 & 0.41 & $0.97(0.94-0.98)$ & 0.20 & 0.001 & $0.94(0.68-0.98)$ & 0.48 & $<0.001$ \\
\hline & $\mathrm{nLn}-\mathrm{Pu}$ & $0.98(0.96-0.99)$ & 0.08 & 0.18 & $0.98(0.96-0.99)$ & -0.07 & 0.27 & $0.87(0.77-0.93)$ & 0.15 & 0.29 \\
\hline \multirow[t]{4}{*}{ LDT } & $\mathrm{dPc}-\mathrm{Pu}^{\prime}$ & $0.98(0.96-0.99)$ & 0.11 & 0.14 & $0.95(0.90-0.97)$ & -0.11 & 0.35 & $0.77(0.59-0.87)$ & 0.14 & 0.52 \\
\hline & $\mathrm{dLn}-\mathrm{Pu}^{\prime}$ & $0.98(0.96-0.99)$ & 0.08 & 0.36 & $0.97(0.94-0.98)$ & -0.22 & 0.33 & $0.78(0.59-0.88)$ & -0.01 & 0.98 \\
\hline & $\mathrm{n} * \mathrm{Pc}-\mathrm{Pu}$ & $0.98(0.97-0.99)$ & 0.06 & 0.28 & $0.98(0.95-0.99)$ & -0.34 & $<0.001$ & $0.78(0.60-0.88)$ & 0.09 & 0.59 \\
\hline & $\mathrm{n} * \mathrm{Ln}-\mathrm{Pu}$ & $0.95(0.92-0.97)$ & 0.17 & 0.07 & $0.93(0.88-0.96)$ & 0.04 & 0.74 & $0.65(0.36-0.81)$ & 0.42 & 0.06 \\
\hline
\end{tabular}

NP Neutral Position; LDT Lateral Distraction Test

Table 5 Intra-rater, inter-rater reliability and inter-methods reliability of all measurements on 3D images

\begin{tabular}{|c|c|c|c|c|c|c|c|c|c|c|c|c|c|}
\hline \multicolumn{2}{|c|}{ Landmarks } & \multicolumn{4}{|c|}{ Intra-rater } & \multicolumn{4}{|c|}{ Inter-rater } & \multicolumn{4}{|c|}{ Inter-methods } \\
\hline & & MAD & RED & TED & $\%$ TEM & MAD & RED & TED & $\%$ TEM & MAD & REM & TEM & $\%$ TEM \\
\hline \multirow[t]{2}{*}{ NP } & $\mathrm{nPc}-\mathrm{Pu}$ & 0.26 & 2.76 & 0.30 & 3.17 & 0.36 & 3.82 & 0.28 & 2.91 & 0.24 & 2.59 & 0.17 & 1.83 \\
\hline & $\mathrm{nLn}-\mathrm{Pu}$ & 0.27 & 6.99 & 0.31 & 8.15 & 0.34 & 9.00 & 0.26 & 6.76 & 0.24 & 6.13 & 0.17 & 4.34 \\
\hline \multirow[t]{4}{*}{ LDT } & $\mathrm{dPc}-\mathrm{Pu}$ & 0.41 & 6.21 & 0.39 & 6.00 & 0.50 & 7.5 & 0.62 & 9.52 & 0.83 & 12.04 & 1.11 & 16.05 \\
\hline & $\mathrm{dLn}-\mathrm{Pu}$ & 0.41 & 24.76 & 0.37 & 24.02 & 0.40 & 25.65 & 0.32 & 18.88 & 0.59 & 30.39 & 0.52 & 26.85 \\
\hline & $\mathrm{n} * \mathrm{Pc}-\mathrm{Pu}$ & 0.30 & 3.29 & 0.26 & 2.86 & 0.28 & 3.12 & 0.24 & 2.60 & 0.43 & 4.56 & 0.98 & 4.00 \\
\hline & $\mathrm{n} * \operatorname{Ln}-\mathrm{Pu}$ & 0.47 & 13.41 & 0.42 & 12.07 & 0.50 & 13.79 & 0.54 & 14.90 & 0.69 & 9.27 & 0.37 & 13.07 \\
\hline
\end{tabular}

NP Neutral Position; LDT Lateral Distraction Test

had a REM between 1 and 4\%, two measurements (distance from limbus to punctum in NP and distraction distance from pupil center to lower punctum in LDT) had a REM between 4 and 7\%. Two measurements (normal distance from limbus to punctum in LDT and distraction distance from nasal limbus to lower punctum in LDT) had a REM over $10 \%$. The TEM was less than $1 \mathrm{~mm}(<1$ unit) for all the six measurements. Two measurements (distance from pupil center to punctum both in NP and LDT) had a $\%$ TEM was between 1 and 4\%. Measurement of distance from pupil center to lower punctum in LDT had a \% TEM between 4 and $7 \%$ and the measurement from limbus nasal center to punctum in NP had a \% TEM between 7 and $10 \%$. The \% TEM for normal distance from limbus to punctum in distraction position and the distraction distance from nasal limbus to lower punctum were over $10 \%$ (Table 5).

\section{Inter-Rater Reliability for 3D-LDT}

Inter-class correlation (ICC) for 3D image measurements were greater than or equal to 0.95 for 5 of the 6 measurements, between 0.90 and 0.94 for the distance from nasal limbus to punctum in the LDT (Table 4).

MAD were less than $1 \mathrm{~mm}$ for all the 6 measurements. Two measurements (distance from pupil center to punctum in both NP and LDT) of the six measurements had a REM between 1 and 4\%, two measurements (distance from limbus to punctum in NP and distraction distance from pupil center to lower punctum) had a REM between 7 and $10 \%$. The REM for normal distance from limbus to punctum in LDT and the distraction distance from nasal limbus to lower punctum were over $10 \%$.

The TEM was less than $1 \mathrm{~mm}$ for all the six measurements. Two measurements (distance from pupil center to punctum both in the NP and LDT) of the six measurements had a \% TEM between 1 and 4\%. The measurements of distance from limbus to punctum in NP, and the measurement of distraction distance from pupil center to lower punctum LDT were between 4 and 10\%. The \% TEM for normal distance from limbus to punctum in LDT and the distraction distance from nasal limbus to lower punctum were over $10 \%$ (Table 5). 


\section{Inter-Method Reliability for 3D-LDT}

Intraclass correlation (ICC) comparing observer one and observer two for all participants were greater than 0.90 for distance from pupil center to punctum in NP; between 0.80 and 0.89 for distance from limbus to punctum in rest position; and between 0.70 and 0.80 for the normal distance from pupil center and nasal limbus to punctum in LDT, and distraction distance from pupil center to punctum in LDT, and less than 0.70 for the distraction distance from nasal limbus to punctum in LDT (Table 4).

MAD were less than $1 \mathrm{~mm}$ for all the 6 measurements. The measurement of the distance from pupil center to punctum in NP had a REM between 1 and 4\%. Two measurements (distance from nasal limbus to punctum in NP and LDT) had a REM between 4 and 7\%. The REM for normal distance from limbus to punctum in LDT was between 7 and $10 \%$. The distraction distance from pupil center to lower punctum was $12.04 \%$, and the REM for distraction distance from nasal limbus to lower punctum was over $30 \%$. The TEM was less than $1 \mathrm{~mm}$ for five of the six measurements. One measurement for the distraction distance from pupil center to punctum in LDT had a TEM of $1.11 \mathrm{~mm}$. Two measurements (distance from pupil center to punctum both in NP and LDT) of the six measurements had a \%TEM between 1 and $4 \%$. The measurement of distance from limbus to punctum in NP had a $\%$ TEM of between 4 and 7\%. Both the \%TEM for distraction distance from pupil center and normal distance from nasal limbus to punctum in LDT were between 10 and $20 \%$. The \% TEM for distraction distance from nasal limbus to lower punctum in LDT were over 20\%. (Table 5).

\section{Discussion}

All the anthropometric measurements for the punctum position taken on 3D images by means of the VECTRA ${ }^{\mathrm{M} 3}$ System in NP demonstrated high reliability (Table 5), consistent with the previous studies using this system in our research group for the periocular anthropometry $[13,27,28]$. All the measurements in the LDT observed by this indirect way of VECTRA ${ }^{\mathrm{M} 3}$ System also demonstrated high reliability, despite the relatively poor result for the distance from limbus nasal center to the lower punctum (Table 4). Digital image processing techniques have been successfully used to examine the palpebral contour in different pathologies of the eyelid position [33]. Additionally, Daniella de Paiva Almeida Stuchi et al, investigated the intra- and inter-observer reliability of a modified distraction test based on the 3D imaging technique for assessing the horizontal tension of lower eyelid [34]. However, no studies used digital images to analyze the medial canthal tension laxity so far. Moreover, previous studies on the MCT laxity were only qualitatively graded $[8,35,36]$. To the best of our knowledge, this is the first study investigating the reliability of using 3D image for analyzing the MCT laxity. Furthermore, our study firstly demonstrated the mean NP and distraction position of the lower punctum in a quantitative way in a normal population.

Our study showed that almost all measurements originated from the NP had higher reliability (MAD, REM, TEM, \%TEM and ICC) than those originated from the LDT (Table 5), particularly within the intra-observer and inter- method categories. Clearly, the 3D images taken in the NP avoid the bias that may be caused by the image torsion when performing the LDT. Images taken in NP provided the overall better precision than in the distraction test. These results suggest that the VECTRA ${ }^{\mathrm{M} 3}$ System is capable of excellent reliability for the evaluation the punctum position for the normal population or patients with lower eyelids diseases. More specifically, the results could be introduced to further evaluation for lower eyelid diseases such as ectropion especially for patients with medial ectropion or symptom of epiphora, and so on.

For all the digital images, we set two different distance ( $\mathrm{Pc}-\mathrm{Pu}$ and $\mathrm{Ln}-\mathrm{Pu}$ ) according to two reference vertical lines, with one across the pupil center $(\mathrm{Pc})$ and another across the corneal limbus nasal center (Ln). Previous studies $[8,11,37]$ normally used the vertical line across the corneal limbus nasal center to define the resting position or the distraction distance of the lower punctum in the direct measurements. However, in the indirect way of using 3D images [13, 27, 28, 34], pupil center was the basement for almost all the landmarks. Hence, we developed a reliability comparison between the two reference vertical lines. In our study, measurements for both vertical lines demonstrated high score of ICC in intra- rater, inter-rater and intermethod, despite the significant difference of $\mathrm{nPc}-\mathrm{Pu}$ for inter-methods reliability and $\mathrm{n} * \mathrm{Pc}-\mathrm{Pu}$ for intra-rater reliability, which were not clinically significant $(\leq 1 \mathrm{~mm})$ for all of them (Table 5). Additionally, no significant difference was found between them in NP for MAD, REM, TEM and \%TEM in intra- rater, inter-rater and inter-method reliability (Table 4). Admittedly, the score of inter-methods reliability for $\mathrm{n}^{*} \mathrm{Pc}-\mathrm{Pu}$ and $\mathrm{dPc}-\mathrm{Pu}^{\prime}$ was relatively higher than those of intra- and inter-rater reliability, despite individual observers having trained together. Nevertheless, in the distraction test, the overall reliability of the distance according to limbus nasal center was lower than that of pupil center, which indicated that the distraction distance calculated from the pupil center was more reliable and repeatable for the evaluation of the MCT laxity than that from the limbus nasal center to the lower punctum (Table 4). 
Furthermore, our study demonstrated the possibilities in the application for different pathological conditions. Evaluation of lower eyelid malpositions plays a vital role in the diagnosing of eyelid disease as well as the designation of surgeries, and the follow-up project is also essential for the evaluation of treatment effects. However, the main evaluation of lower eyelid malpositions, especially the medial canthal malposition is not quantitative due to the limited method [38]. In our study, with the application of the 3D stereophotography and our landmarks system, the pre-operative malposition could be evaluated quantitatively (Fig. 3), and the post-operative follow-up could be recorded for quantitative observation and comparison (Fig. 4). Additionally, the findings of the present study build the essential basis to introduce this novel 3D-LDT in the clinical routine and to conduct follow-up projects investigating variations of repair techniques and their failure rate.

The possible limitation of this study might be the challenge to keep the participants looking into the same position when performing the LDT, especially for the sensitive ones. For optimal image, an individual being captured must keep a consistent head position and visual focus direction. To minimize errors caused by the processing of LDT, repeated captures and cooperative with another operator are necessary.

In conclusion, the high intra-rater, inter-rater and intermethod reliability found in this study was due to the easy application of the technique and analysis of the results. Our novel standardized three-dimensional lateral distraction test (3D-LDT) seems to be a feasible and highly reliable method to assess medial canthal tendon (MCT) laxity. Furthermore, pathological eyelid conditions were not included in this study for the identification error of all the landmarks. Therefore, follow-up studies are necessary to investigate the reliability of this 3D-LDT on pathological cases as well as to evaluate the correlation of these measurements with subjective patients' complaints and various disease severity of eyelid abnormalities. Lastly, to our best knowledge, this is the first study quantifying the reliability of the 3D-LDT for evaluating the MCT laxity based on digital image processing.

Funding Open Access funding enabled and organized by Projekt DEAL. This study was supported by the "Fundamental Research Funds for the Central Universities" (2021FZZX005-15); National Natural Science Foundation of China (No. 81970834); Science and Technology Commission of Shanghai Municipality (No. 19441900800). The funding organizations had no role in the design or conduct of this research.

Data Availability All authors have full control of all primary data and they agree to allow to review their data upon request.

\section{Declarations}

Conflict of interest The authors declare that they have no conflicts of interest to disclose.

Ethical Approval The study protocol adhered to the Declaration of Helsinki and was approved by the Institutional Review Board of the University of Cologne.

Informed Consent Informed consents were obtained from all the participants.

Open Access This article is licensed under a Creative Commons Attribution 4.0 International License, which permits use, sharing, adaptation, distribution and reproduction in any medium or format, as long as you give appropriate credit to the original author(s) and the source, provide a link to the Creative Commons licence, and indicate if changes were made. The images or other third party material in this article are included in the article's Creative Commons licence, unless indicated otherwise in a credit line to the material. If material is not included in the article's Creative Commons licence and your intended use is not permitted by statutory regulation or exceeds the permitted use, you will need to obtain permission directly from the copyright holder. To view a copy of this licence, visit http://creativecommons. org/licenses/by/4.0/.

\section{References}

1. Robinson TJ, Stranc MF (1970) The anatomy of the medial canthal ligament. Br J Plast Surg 23(1):1-7

2. Jones LT, Reeh MJ, Tsujimura JK (1963) Senile entropion. Am J Ophthalmol 55:463-469

3. Damasceno RW, Avgitidou G, Belfort R Jr, Dantas PE, Holbach LM, Heindl LM (2015) Eyelid aging: pathophysiology and clinical management. Arq Bras Oftalmol 78(5):328-331

4. Anderson RL, Hatt MU, Dixon R (1979) Medial ectropion. A new technique. Arch Ophthalmol 97(3):521-524

5. Bergstrom R and Czyz CN, Ectropion Lower Eyelid Reconstruction, in StatPearls. 2020: Treasure Island (FL)

6. Frueh BR, Schoengarth LD (1982) Evaluation and treatment of the patient with ectropion. Ophthalmology 89(9):1049-1054

7. O'Donnell B (1994) Age-related medial ectropion of the lower eyelid. Aust N Z J Ophthalmol 22(3):183-186

8. Olver JM, Sathia PJ, Wright M (2001) Lower eyelid medial canthal tendon laxity grading: an interobserver study of normal subjects. Ophthalmology 108(12):2321-2325

9. Liu D, Stasior OG (1983) Lower eyelid laxity and ocular symptoms. Am J Ophthalmol 95(4):545-551

10. Manners RM (1995) Surgical repair of medial ectropion. Eye 9(3):365-367

11. Clement CI, O’Donnell BA (2004) Medial canthal tendon repair for moderate to severe tendon laxity. Clin Exp Ophthalmol 32(2):170-174

12. Patipa M (2000) The evaluation and management of lower eyelid retraction following cosmetic surgery. Plast Reconstr Surg 106(2):438-53

13. Guo Y, Hou X, Rokohl AC, Jia R, Heindl LM (2019) Reliability of periocular anthropometry: a comparison of direct, 2-dimensional, and 3-dimensional techniques. Dermatol Surg 46(9):e23e31

14. Weinberg SM, Scott NM, Neiswanger K, Brandon CA, Marazita ML (2004) Digital three-dimensional photogrammetry: evaluation of anthropometric precision and accuracy using a Genex 3D camera system. Cleft Palate Craniofac J 41(5):507-518

15. Aldridge K, Boyadjiev SA, Capone GT, DeLeon VB, Richtsmeier JT (2005) Precision and error of three-dimensional 
phenotypic measures acquired from 3dMD photogrammetric images. Am J Med Genet A 138A(3):247-253

16. Geil MD (2007) Consistency, precision, and accuracy of optical and electromagnetic shape-capturing systems for digital measurement of residual-limb anthropometrics of persons with transtibial amputation. J Rehabil Res Dev 44(4):515-524

17. Wong JY, Oh AK, Ohta E, Hunt AT, Rogers GF, Mulliken JB, Deutsch CK (2008) Validity and reliability of craniofacial anthropometric measurement of 3D digital photogrammetric images. Cleft Palate Craniofac J 45(3):232-239

18. Metzler P, Sun Y, Zemann W, Bartella A, Lehner M, Obwegeser JA, Kruse-Gujer AL, Lubbers HT (2014) Validity of the 3D VECTRA photogrammetric surface imaging system for craniomaxillofacial anthropometric measurements. Oral Maxillofac Surg 18(3):297-304

19. Krimmel M, Kluba S, Dietz K, Reinert S (2005) Assessment of precision and accuracy of digital surface photogrammetry with the DSP 400 system. Biomed Tech 50(3):45-53

20. Kim SH, Jung WY, Seo YJ, Kim KA, Park KH, Park YG (2015) Accuracy and precision of integumental linear dimensions in a three-dimensional facial imaging system. Korean J Orthod 45(3):105-112

21. Burke PH and Beard LF (1967). Stereo-photogrammetry of the face. A preliminary investigation into the accuracy of a simplified system evolved for contour mapping by photography. Am J Orthod 53(10):769-782.

22. Burke PH, Banks P, Beard LF, Tee JE, Hughes C (1983) Stereophotographic measurement of change in facial soft tissue morphology following surgery. Br J Oral Surg 21(4):237-245

23. Motoyoshi M, Namura S, Arai HY (1992) A three-dimensional measuring system for the human face using three-directional photography. Am J Orthod Dentofacial Orthop 101(5):431-440

24. Ferrario VF, Sforza C, Poggio CE, Serrao G, Miani A Jr (1994) A three-dimensional study of sexual dimorphism in the human face. Int J Adult Orthodon Orthognath Surg 9(4):303-310

25. Ferrario VF, Sforza C, Poggio CE, Serrao G (1996) Facial threedimensional morphometry. Am J Orthod Dentofacial Orthop. 109(1):86-93

26. Meintjes EM, Douglas TS, Martinez F, Vaughan CL, Adams LP, Stekhoven A, Viljoen D (2002) A stereo-photogrammetric method to measure the facial dysmorphology of children in the diagnosis of fetal alcohol syndrome. Med Eng Phys 24(10):683-689

27. Guo Y, Rokohl AC, Schaub F, Hou X, Liu J, Ruan Y, Jia R, Koch KR, Heindl LM (2019) Reliability of periocular anthropometry using three-dimensional digital stereophotogrammetry. Graefes Arch Clin Exp Ophthalmol 257(11):2517-2531
28. Guo Y, Schaub F, Mor JM, Jia R, Koch KR, Heindl LM (2020) A simple standardized three-dimensional anthropometry for the periocular region in a european population. Plast Reconstr Surg 145(3):514e-523e

29. Heike CL, Cunningham ML, Hing AV, Stuhaug E, Starr JR (2009) Picture perfect? Reliability of craniofacial anthropometry using three-dimensional digital stereophotogrammetry. Plast Reconstr Surg 124(4):1261-1272

30. Weinberg SM, Naidoo S, Govier DP, Martin RA, Kane AA, Marazita ML (2006) Anthropometric precision and accuracy of digital three-dimensional photogrammetry: comparing the Genex and 3dMD imaging systems with one another and with direct anthropometry. J Craniofac Surg 17(3):477-483

31. Andrade LM, Rodrigues da Silva AMB, Magri LV, Rodrigues da Silva MAM (2017) Repeatability study of angular and linear measurements on facial morphology analysis by means of stereophotogrammetry. J Craniofac Surg 28(4):1107-1111

32. Camison L, Bykowski M, Lee WW, Carlson JC, Roosenboom J, Goldstein JA, Losee JE, Weinberg SM (2018) Validation of the Vectra $\mathrm{H} 1$ portable three-dimensional photogrammetry system for facial imaging. Int J Oral Maxillofac Surg 47(3):403-410

33. Cruz AA, Coelho RP, Baccega A, Lucchezi MC, Souza AD, Ruiz EE (1998) Digital image processing measurement of the upper eyelid contour in Graves disease and congenital blepharoptosis. Ophthalmology 105(5):913-918

34. Stuchi DPA, Rossato J, Bocaccio FJL, Procianoy F (2020) Intraand interobserver reliability of a modified distraction test based on digital images to assess lower eyelid horizontal tension. Arq Bras Oftalmol 83(2):127-131

35. Czyz CN, Wulc AE, Ryu CL, Foster JA, Edmonson BC (2015) Caruncular fixation in medial canthal tendon repair: the minimally invasive purse string suture for tendinous laxity and medial ectropion. Ophthalmic Plast Reconstr Surg 31(1):34-37

36. Rozycki R, Zelichowska B (2005) Evaluation of the medial canthus blepharoplasty using the lazy-T method. Klin Oczna 107(4-6):354-357

37. Fong KC, Mavrikakis I, Sagili S, Malhotra R (2006) Correction of involutional lower eyelid medial ectropion with transconjunctival approach retractor plication and lateral tarsal strip. Acta Ophthalmol Scand 84(2):246-249

38. Baek S, Chung J-H, Yoon E-S, Lee B-I, Park S-H (2018) Algorithm for the management of ectropion through medial and lateral canthopexy. Arch Plast Surg 45(6):525-533

Publisher's Note Springer Nature remains neutral with regard to jurisdictional claims in published maps and institutional affiliations. 